\title{
Determination of Bacteria associated with Urinary Catheters from Patients Suffering from Urinary Tract Infections
}

\author{
Mohammed Bashir ${ }^{1, *}$, Abubakar Babajo Umar ${ }^{2}$, Mohammed Bilyaminu ${ }^{2}$ \\ ${ }^{1}$ Department of Microbiology, Modibbo Adama University of Technology, Yola, Nigeria \\ ${ }^{2}$ Department of Science Laboratory Technology, Modibbo Adama University of Technology, Yola, Nigeria
}

\section{ARTICLE INFO}

\section{Article History}

Received 01 October 2019

Accepted 08 February 2020

\section{Keywords}

Urinary catheters

urinary tract infection

UTI patients

prevalence

CAUTIs

uropathogens

\begin{abstract}
Urinary catheters act as a reservoir of resistant pathogens. Several factors (type, duration, procedural mistakes during insertion of catheter, associated diseases of patients, etc.) are responsible for the different catheter-associated urinary tract infection (CAUTI) rates in different healthcare setups. This study was conducted to determine bacteria that can be found in the urinary catheter of UTI patients. The samples were aseptically collected into a sterile container $48 \mathrm{~h}$ after insertion of catheter. Urine culture was done on blood agar and cystine-lactose-electrolyte-deficient agar. However, standard protocol of identification was done to identify the isolates. The highest prevalence in relation to age in this study was obtained in age groups $21-30$ and 41-50 years, each with $11(23.40 \%)$ uropathogens, and the lowest was obtained in the 71-80 years age bracket with zero prevalence. A higher number of uropathogens was found in female participants (26,55.32\%) than in male patients $(21,44.68 \%)$. However, different types of bacteria such as Escherichia coli, Proteus mirabilis, Pseudomonas aeruginosa, Staphylococcus aureus, Proteus vulgaris, Klebsiella pneumoniae, and Staphylococcus saprophyticus were isolated from catheters of UTI patients. Among the isolates, higher prevalence was found in E. coli in both male and female patients with a frequency of seven/21 (33.33\%) and eight/26 (30.77\%), respectively, followed by S. aureus with six/21 (28.57) and five/26 (19.23) in male and female patients, respectively. Catheterization of UTI patients is a very common procedure used in many hospitals, and practice is even more common in the intensive care units of most hospitals.
\end{abstract}

(C) 2020 Dr. Sulaiman Al Habib Medical Group. Publishing services by Atlantis Press International B.V. This is an open access article distributed under the CC BY-NC 4.0 license (http://creativecommons.org/licenses/by-nc/4.0/).

\section{INTRODUCTION}

The urinary catheter is a tube that is inserted into the bladder through the urethra of patients suffering from Urinary Tract Infection (UTI) in order to drain urine. The most commonly known urinary catheter is the Foley catheter, which is generally made of up rubber, plastic, silicone, or latex. A Foley catheter is a double lumen (tube) catheter; the larger lumen drains urine from the bladder, and the smaller lumen is used to inflate the small balloon at the tip of the catheter [1]. Catheter-associated UTIs (CAUTI) contributes approximately $30-35 \%$ of all hospital-acquired infections (HAIs) [2]. Presence of indwelling catheter is a prerequisite for CAUTI, and risk of CAUTIs varies from 3\% to $7 \%$ daily [3]. However, using catheter for more than 2 days can be a significant factor for CAUTI [4]. This is as a result of the organisms attached to the catheter surfaces, leading to the formation of biofilms on the catheter, which can in turn lead to CAUTIs. Elderly individuals, people with diabetes, being female, obesity, etc., are the other risk factors [5]. Although

Corresponding author.Email: mbashir@mautech.edu.ng

Peer review under responsibility of the Dr. Sulaiman Al Habib Medical

Services Group Company

Data availability statement: The authors of this article wishes to confirm that all the data supporting the findings of this study are available within the article and/or its supplementary materials. All the data that were used to support the findings of this study were properly cited within the text and they are also reference properly in the reference section of the work.
CAUTIs can be caused by both gram-positive and -negative bacteria, most are usually caused by gram-negative bacteria, such as Escherichia coli, Enterococcus species, Pseudomonas aeruginosa, and Klebsiella pneumoniae [2].

Use of urinary catheters when required, insertion with full aseptic procedure, properly secured catheter, removal of catheter as soon as possible, and maintenance of unrestricted urine flow are important for prevention of CAUTIs [3]. A higher rate of infection often leads to increased rates of antimicrobial prescription, which in turn contributes to increase in antimicrobial resistance [6]. This study was designed to determine and detect the different bacteria that are associated with urinary catheters from patients with UTI.

\section{MATERIALS AND METHODS}

\subsection{Sample Collection}

This study was carried out in Jimeta, Yola, in Adamawa state Nigeria. A total of 50 urine samples were aseptically collected into sterile containers from catheterized patients $48 \mathrm{~h}$ after catheter insertion in Dawa'u and Meddy clinics within the Jimeta metropolis [7]. 


\subsection{Isolation of Bacteria from Urine Samples}

The urine sample was inoculated and streaked using a sterile wire loop onto cystine-lactose-electrolyte-deficient agar as well as blood agar. The inoculated plates were incubated in an incubator at $37^{\circ} \mathrm{C}$ for $18-24 \mathrm{~h}$ using standard laboratory techniques [8].

\subsection{Identification of Bacteria from Urine Samples}

The bacterial isolates were then identified using the standard identification procedure. The bacterial isolates were identified on the basis of their cultural characteristics, microscopy, and certain biochemical tests as described by Cheesbrough [8].

\subsection{Statistical Analysis}

The data generated were analyzed using the MacChi-square descriptive statistics method; the levels of significance were expressed as $p$-value. When the $p$-value is $<0.05$, it is considered statistically significant.

\section{RESULTS}

Urine samples were observed to have different colors, and results of this observation are shown in Table 1 . Twenty-five (50\%) of the urine samples were yellow, nine $(18.0 \%)$ were pale yellow, nine $(18.0 \%)$ were white, and seven $(14.0 \%)$ were red.

\subsection{Color of Urine Samples}

Details on the color of urine samples are shown in Table 1.

\subsection{Appearance of Urine Samples}

The appearance of the urine samples was observed; 29 (58.0\%) of the samples had a clear appearance whereas $21(42.0 \%)$ were described as turbid (Table 2).

Table 1 Color of urine samples

\begin{tabular}{lcc}
\hline Color & No. of samples & Frequency (\%) \\
\hline Yellow & 25 & 50.00 \\
Pale yellow & 9 & 18.00 \\
White & 9 & 18.00 \\
Red & 7 & 14.00 \\
Total & 50 & 100 \\
\hline
\end{tabular}

Chi-square $=0.000, d f=3, p=0.9999$.

Table 2 Appearance of urine samples

\begin{tabular}{lcc}
\hline Appearance & No. of urine samples & Frequency (\%) \\
\hline Clear & 29 & 58.00 \\
Turbid & 21 & 42.00 \\
Total & 50 & 100 \\
\hline
\end{tabular}

Chi-square $=0.000, d f=1, p=0.9999$.

\subsection{Sex Distribution}

The sex distribution of the study participants is described in Table 3. The study group consisted of 19 (38.0\%) male and 31 $(62.0 \%)$ female volunteers.

\subsection{Age Distribution}

The number of uropathogens isolated in relation to the age distribution of the study participants is presented in Table 4 . The results revealed that the highest prevalence was in the 21-30 years and 41-50 years age groups, with 11 uropathogens isolated from each group. Meanwhile, the lowest number of uropathogens was found in the 71-80 years age group with zero isolate.

\subsection{Biochemical Analysis}

Table 5 shows the results of the biochemical identification of isolates. Several biochemical tests were conducted, and results showed that several bacteria were associated with urinary catheters. Although these organisms included both gram-positive and -negative bacteria, the most prevalent were gram-negative bacteria such as E. coli, K. pneumoniae, Proteus mirabilis, Proteus vulgaris, and $P$. aeruginosa. Meanwhile, the gram-positive bacteria included Staphylococcus aureus and Staphylococcus saprophyticus.

\subsection{Prevalence of Uropathogen in Relation to Sex}

The prevalence of uropathogens in relation to sex of the study participants is given in Table 6 . The results showed that in both male and female participants, E. coli has the highest prevalence, with $14.89 \%$ and $17.02 \%$ for male and female participants, respectively. Meanwhile, S. saprophyticus has the lowest prevalence among male participants ( $0 \%$ prevalence).

Table 3 Sex distribution of study population

\begin{tabular}{lcc}
\hline Sex & No. of participants & Frequency (\%) \\
\hline Male & 19 & 38.00 \\
Female & 31 & 62.00 \\
Total & 50 & 100 \\
\hline
\end{tabular}

Chi-square $=0.000, d f=1, p=0.9999$.

Table 4 Age distribution of study population

\begin{tabular}{lcc}
\hline Age (years) & No. of uropathogen & Frequency (\%) \\
\hline $10-20$ & 6 & 12.77 \\
$21-30$ & 11 & 23.40 \\
$31-40$ & 6 & 12.77 \\
$41-50$ & 11 & 23.40 \\
$51-60$ & 4 & 8.51 \\
$61-70$ & 7 & 14.89 \\
$71-80$ & 0 & 0.00 \\
$81-90$ & 2 & 4.26 \\
Total & 47 & 100 \\
\hline
\end{tabular}

Chi-square $=0.000, d f=7, p=0.001$. 
Table 5 Results of biochemical analysis

\begin{tabular}{|c|c|c|c|c|c|c|c|c|c|c|c|}
\hline \multirow[b]{2}{*}{$\mathbf{S} / \mathbf{N}$} & \multirow{2}{*}{$\begin{array}{c}\text { Gram } \\
\text { staining }\end{array}$} & \multicolumn{9}{|c|}{ Biochemical test } & \multirow[b]{2}{*}{ Suspected organism } \\
\hline & & Catalase & Indole & Urease & Citrase & $\begin{array}{l}\text { Nitrate } \\
\text { reduction }\end{array}$ & Coagulase & Oxidase & $\begin{array}{l}\text { Methyl } \\
\text { red }\end{array}$ & $\begin{array}{c}\text { Novobiocin } \\
\text { susceptibility }\end{array}$ & \\
\hline 1 & - Rod & + & + & - & - & + & - & - & - & $\mathrm{Nt}$ & Escherichia coli \\
\hline 2 & - Rod & + & - & + & + & + & + & - & - & $\mathrm{Nt}$ & Klebsiella pneumoniae \\
\hline 3 & + Cocci & + & - & - & - & - & + & - & + & S & Staphylococcus aureus \\
\hline 4 & $-\operatorname{Rod}$ & - & - & + & + & + & - & - & + & $\mathrm{Nt}$ & Proteus mirabilis \\
\hline 5 & -Rod & + & + & + & - & + & - & + & + & $\mathrm{Nt}$ & Proteus vulgaris \\
\hline 6 & + Cocci & + & - & + & - & - & - & - & + & $\mathrm{R}$ & Staphylococcus saprophyticus \\
\hline 7 & $-\operatorname{Rod}$ & - & - & - & + & - & - & + & - & $\mathrm{Nt}$ & Pseudomonas aeruginosa \\
\hline
\end{tabular}

+, positive; -, negative; $\mathrm{Nt}$, not tested; R, resistance; $\mathrm{S}$, susceptible.

Table 6 Prevalence of uropathogen in relation to sex

\begin{tabular}{lccccc}
\hline \multirow{2}{*}{ Organisms } & \multicolumn{3}{c}{ Male } & & \multicolumn{2}{c}{ Female } \\
\cline { 2 - 3 } \cline { 5 - 6 } \cline { 5 - 6 } & No. of organisms & Prevalence (\%) & & No. of organisms & Prevalence (\%) \\
\hline Escherichia coli & 7 & 33.33 & & 8 & 30.77 \\
Staphylococcus aureus & 6 & 28.57 & & 5 & 19.23 \\
Pseudomonas aeruginosa & 2 & 9.52 & & 2 & 7.69 \\
Proteus mirabilis & 2 & 9.52 & & 3 & 7.54 \\
Proteus vulgaris & 3 & 14.29 & & 2 & 7.69 \\
Klebsiella pneumoniae & 1 & 0.76 & & 2 & 15.39 \\
Staphylococcus saprophyticus & 0 & 100 & & 26 & 100 \\
Total & 21 & & & & \\
\hline
\end{tabular}

Chi-square $=4.409, d f=6, p=0.6215$.

\section{DISCUSSION}

Different gram-negative and -positive bacteria are responsible for CAUTI in patients suffering from UTI. However, the most commonly encountered bacteria are gram-negative bacteria such as E. coli, $P$. aeruginosa, K. pneumoniae, $P$. mirabilis, and $P$. vulgaris [9]. The age distribution of the study participants was presented at an interval of 10 years; the higher prevalence of bacteria associated with UTIs was found in the age groups 21-30 years and 41-50 years, each with 11/47 (23.40\%) uropathogens. However, in a study conducted by Adane et al. [10], the age groups of 25-44 years and 45-64 years had higher UTI infection rate compared with other age groups. This difference could be attributed to differences in class interval used in these studies. In a previous study conducted in Bushenyi, Uganda, Martin et al. [11] reported a prevalence of (32.2\%), which is higher than the prevalence obtained in the present study. Significant bacteriuria of 29/40 (72.5\%) in asymptomatic patients was also reported in a previous study [12]. In another study conducted in Mulago, higher proportions of females were found to have higher risk of CAUTI [13].

However, in terms of the sex status of study participants, female participants were found to have a higher prevalence of CAUTIs than their male counterparts. This study shows that the majority of UTIs were found in females, which indicates that women are more likely to develop UTIs than men. The result of this study is in line with that of another study [14], which also discovered that women are more prone to UTI infections than men. Women are more prone to develop UTI than men probably because of their anatomical and physiological characteristics [15].

Escherichia coli is the most prevalent bacterial uropathogen associated with CAUTI $(7 / 21 ; 14.89 \%)$. This is in agreement with other studies reporting that $E$. coli is the most prevalent uropathogen associated with UTIs, with a percentage frequency of $40-46 \%$ [16-18]. Furthermore, the proximity of the anus to the female vagina is a very important factor that accounts for the higher prevalence of UTIs in women. Moreover, our study reported a high prevalence of $E$. coli in females, which also supports the findings of previous studies. However, this high prevalence of UTIs in females can also be attributed to the inherent virulence of $E$. coli for urinary tract colonization such as its ability to adhere to the urinary tract in females and its ability to associate with other microorganisms moving from the perineum areas contaminated with fecal microbes to the moist warmth environment of the female genitalia $[19,20]$.

Among the gram-positive bacteria isolated in this study, S. aureus was found to be the second most frequently found uropathogen. S. aureus had a frequency of six/21 (28.57\%) and five/26 (19.23\%) for male and female participants, respectively. A higher prevalence of $S$. aureus was also reported by Martin et al. [11], in a study they conducted in Bushenyi, Uganda, with a frequency of 27/86 (31.4\%). However, several studies have reported a higher frequency of S. aureus in UTIs. An earlier study performed in Awka, Nigeria, also reported a high frequency rate of $S$. aureus of 60/215 (28.00\%) [21]. Bladder catheter contributes immensely to the increasing populations of $S$. aureus in UTIs $[22,23]$.

Other uropathogens including P. aeruginosa, P. mirabilis, P. vulgaris, K. pneumoniae, and S. saprophyticus were also isolated in this study. Previous studies conducted by Alsammani et al. [24] also showed that $P$. aeruginosa, K. pneumoniae, and $P$. mirabilis were associated with uropathogens. In addition, a study conducted by Ochada et al. [25] in two teaching hospitals at Osun state also reported the presence of K. pneumoniae, $P$. aeruginosa, and $S$. saprophyticus in patients with UTIs. 


\section{CONCLUSION}

The present study revealed the presence of bacteria associated with urinary catheters in individuals with UTIs. The bacteria were found to be more associated with female UTI patients than male UTI patients. This could be because the urethra is very close to the anus in females. Moreover, most frequently isolated uropathogen in this study was E. coli followed by S. aureus.

\section{CONFLICTS OF INTEREST}

The authors declare they have no conflicts of interest.

\section{AUTHORS' CONTRIBUTION}

$\mathrm{MB}, \mathrm{AB}$ and $\mathrm{MBn}$ contributed in conceptualization, designing and writing which includes review and editing the manuscript. $\mathrm{MB}$ and $\mathrm{AB}$ contributed in data collection. MBn contributed in formal analysis. $M B$ writes the original draft. $M B, A B$ and $M B n$ supervised the project. $\mathrm{MB}, \mathrm{AB}$ and $\mathrm{MBn}$ source the funding for the project. However, all the authors review the manuscript and approve the final draft of the manuscript.

\section{ACKNOWLEDGMENTS}

The authors thank the management and staff of both Dawa'u and Meddy clinics for their support and encouragement toward the success of this work. We appreciate their effort.

\section{REFERENCES}

[1] Berman A, Snyder SJ, Kozier B, Erb G. Fundamentals of nursing: Concepts, process and practice, 8th ed. NJ, USA: Pearson Prentice Hall; 2008.

[2] Stone PW, Larson E, Kawar LN. A systematic audit of economic evidence linking nosocomial infections and infection control interventions: 1990-2000. Am J Infect Control 2002;30:145-52.

[3] Gould CV, Umscheid CA, Agarwal RK, Kuntz G, Pegues DA; Healthcare Infection Control Practices Advisory Committee (HICPAC). Guideline for prevention of catheter-associated urinary tract infections 2009. Infect Control Hosp Epidemiol 2010;31:319-26.

[4] Wald HL, Bratzler DW, Ma A, Kramer AM. Indwelling urinary catheter use in the postoperative period: analysis of the national surgical infection prevention project data. Arch Surg 2008;143:551-7.

[5] Tietjen L, Bossemeyer D, McIntosh N. Infection prevention guidelines for healthcare facilities with limited resources. Baltimore, MD: JHPIEGO Corp.; 2003.

[6] Pittet D, Allegranzi B, Storr J, Bagheri Nejad S, Dziekan G, Leotsakos A, et al. Infection control as a major World Health Organization priority for developing countries. J Hosp Infect 2008;68:285-92.

[7] Koneman EW, Allen S, Janda W, Schreckenberger P, Winn WC. Koneman's color atlas and textbook of diagnostic microbiology, 6th ed. New York: Lippincott; 2006, pp. 103-123.
[8] Cheesbrough M. District laboratory practice in tropical countries, 2nd ed. NY, USA: Cambridge University Press; 2009, pp. 132-304.

[9] Foxman B. Epidemiology of urinary tract infections: incidence, morbidity, and economic costs. Am J Med 2002;113:5S-13S.

[10] Bitew A, Molalign T, Chanie M. Species distribution and antibiotic susceptibility profile of bacterial uropathogens among patients complaining urinary tract infections. BMC Infect Dis 2017;17:654.

[11] Odoki M, Almustapha Aliero A, Tibyangye J, Nyabayo Maniga J, Wampande E, Drago Kato C, et al. Prevalence of bacterial urinary tract infections and associated factors among patients attending hospitals in Bushenyi district, Uganda. Int J Microbiol 2019;2019:4246780.

[12] Mwaka AD, Mayanja-Kizza H, Kigonya E, Kaddu-Mulindwa D. Bacteriuria among adult non-pregnant women attending Mulago hospital assessment centre in Uganda. Afr Health Sci 2011;11:182-9.

[13] Kabugo D, Kizito S, Ashok DD, Graham KA, Nabimba R, Namunana S, et al. Factors associated with community-acquired urinary tract infections among adults attending assessment centre, Mulago Hospital Uganda. Afr Health Sci 2016;16:1131-42.

[14] Barate DL, Ukesh C. The bacterial profile and the antibiotic resistance pattern of urinary tract infections. DAV Int J Sci 2012;1:21-4.

[15] Kolawole AS, Kolawole OM, Kandaki-Olukemi YT, Babatunde SK, Durowade KA, Kolawole CF. Prevalence of urinary tract infections (UTI) among patients attending Dalhatu Araf Specialist Hospital, Lafia, Nasarawa State, Nigeria. Int J Med Med Sci 2009;1:163-7.

[16] Kayima JK, Otieno LS, Twahir A, Njenga E. Asymptomatic bacteriuria among diabetics attending Kenyatta National Hospital. East Afr Med J 1996;73:524-6.

[17] Moges AF, Genetu A, Mengistu G. Antibiotic sensitivities of common bacterial pathogens in urinary tract infections at Gondar hospital, Ethiopia. East Afr Med J 2002;79:140-2.

[18] Mayanja R, Kiondo P, Kaddu-Mulindwa, Kaddu S, Ogwang F, Andrew $\mathrm{C}$, et al. The prevalence of asymptomatic bacteriuria and associated factors among women attending antenatal clinics in Lower Mulago Hospital, Uganda. American Scientific Research Journal for Engineering, Technology, and Sciences (ASRJETS) 2016;25:131-48.

[19] McLaughlin SP, Carson CC. Urinary tract infections in women. Med Clin North Am 2004;88:417-29.

[20] Andabati G, Byamugisha J. Microbial aetiology and sensitivity of asymptomatic bacteriuria among ante-natal mothers in Mulago hospital, Uganda. Afr Health Sci 2010;10:349-52.

[21] Ekwealor PA, Ugwu MC, Ezeobi I, Amalukwe G, Ugwu BC, Okezie $U$, et al. Antimicrobial evaluation of bacterial isolates from urine specimen of patients with complaints of urinary tract infections in Awka, Nigeria. Int J Microbiol 2016;2016:9740273.

[22] Moore KN, Day RA, Albers M. Pathogenesis of urinary tract infections: a review. J Clin Nurs 2002;11:568-74.

[23] Iregbu KC, Nwajiobi-Princewill PI. Urinary tract infections in a tertiary hospital in Abuja, Nigeria. Afr J Clin Exp Microbiol 2013;14:169-73

[24] Alsammani MA, Ahmed MI, Abdelatif NF. Bacterial uropathogens isolates and antibiograms in children under 5 years of age. Med Arch 2014;68:239-43.

[25] Ochada NS, Nasiru IA, Thairu Y, Okanlowan MB, Abdulakeem YO. Antimicrobial susceptibility pattern of urinary pathogens isolated from two tertiary hospitals in southwestern Nigeria. Afr J Clin Exp Microbiol 2015;16:12-22. 